\title{
ELABORAÇÃO E AVALIAÇÃO GLOBAL DE BARRA DE CEREAIS CASEIRA
}

\author{
IZABELE PAES DE BRITO * \\ JENYFFER MEDEIROS CAMPOS * \\ TÁBATA FERNANDA LOPES DE SOUZA * \\ CHIKA WAKIYAMA * \\ GEÍZA ALVES DE AZEREDO *
}

\begin{abstract}
Formulou-se receita básica de barra de cereal, empregando biscoito de amido de milho, açúcar demerara, leite em pó desnatado, flocos de arroz, aveia em flocos, xarope de glicose de milho, uva passa e damasco seco, como alternativa às barras encontradas no comércio. Para avaliar a composição centesimal e a aceitação desse produto caseiro foram utilizadas duas barras comerciais como parâmetro de referência. $O$ produto foi submetido à determinações de carboidratos, lipídios, proteínas, fibras e à análise sensorial. Os resultados obtidos demonstraram que a barra formulada apresentou valores bem próximos aos das industrializadas no que se refere ao aporte calórico, carboidratos e proteínas. Entretanto, foram encontrados teores de lipídios $83,0 \%$ a $95,7 \%$ mais baixos que os das barras comerciais. O teor de fibras mostrou-se $14 \%$ menor na barra caseira, sugerindo-se a substituição do biscoito pela versão integral e inserção de cereais integrais na formulação para incrementar o aporte de fibras. A barra formulada obteve aceitação global superior à das barras de referência, representando opção para suplementação de fibras na dieta. Concluiu-se que o produto atende às especificações sanitárias, nutricionais e sensoriais.
\end{abstract}

PALAVRAS-CHAVE: BARRA DE CEREAIS; FIBRA ALIMENTAR; ANÁLISE SENSORIAL.

\section{INTRODUÇÃO}

Aumento significativo no consumo de fast-foods e lanches tem sido verificado nos últimos anos, revelando tendência de mudança no estilo

* Mestrandas em Ciências dos Alimentos, Departamento de Nutrição, Universidade Federal de Pernambuco (UFPE), Recife, PE (e-mail: izabele_ufpe@yahoo.com.br/ tabatalopes@hotmail.com). 
de vida da população (VIEIRA et al., 2001). Isto se deve às facilidades encontradas para a aquisição de alimentos pré-preparados, prontos e congelados no mercado, bem como às inúmeras opções oferecidas por restaurantes fast foode self-service (MATTOS e MARTINS, 2000). Tal realidade está relacionada com a economia no tempo gasto na compra, preparação e consumo de alimentos (VIEIRA et al., 2001).

Dentre os problemas nutricionais que acometem a população, incluindo adolescentes, pode-se destacar o aumento no sobrepeso e a obesidade. Tais problemas são, particularmente, atribuídos ao consumo de alimentos gordurosos, com alta densidade energética e à redução na prática de exercícios físicos (HILL e TRWBRIDGE, 1998). Crianças e adolescentes obesos podem se tornar adultos obesos e apresentar outras patologias associadas à obesidade, tais como hipertensão, dislipidemia e diabetes não-insulino dependente (DIETZ, 1998). A constipação intestinal também representa problema comum entre crianças, principalmente, em idade escolar. No geral, a ingestão aumentada de fibra dietética é recomendada para o tratamento da constipação intestinal de adultos e de crianças (GUIMARÃES; GOULART; PENNA, 2001). Associado a esses fatores, os hábitos alimentares têm demonstrado baixa ingestão de fibras pela população (MATTOS e MARTINS, 2000).

GUIMARÃES, GOULART e PENNA (2001) avaliaram a alimentação de crianças e adolescentes brasileiros entre 4 a 14 anos. Verificaram que a ingestão média de fibra foi de 10,3 $\mathrm{g} / \mathrm{dia}$, e que $18,4 \%$ desses apresentaram ingestão diária abaixo dos níveis recomendados pela American Health Foundation. Outro estudo com crianças (idade média de 6,5 anos) estabeleceu a ligação entre o quadro de constipação intestinal e pouca ingestão de fibras (VÍTOLO et al., 1998).

Em adultos, MATTOS e MARTINS (2000) constataram consumo médio diário da população de $24 \mathrm{~g}$ de fibras totais (sendo $17 \mathrm{~g}$ de insolúveis e $7 \mathrm{~g}$ de solúveis). Verificaram que a maioria dos alimentos presentes na dieta habitual continha baixo teor de fibras, excetuando-se o feijão (principal fonte de fibra na alimentação do brasileiro).

De acordo com PENTEADO (1981), o consumo regular de fibras alimentares tem sido constante nas recomendações feitas por nutricionistas e órgãos oficiais. Tais recomendações baseiam-se na 
constatação de que as fibras alimentares apresentam determinados efeitos responsáveis por alterações significativas na fisiologia humana, atuando na prevenção de doenças crônicas (GUTKOSKI; TROMBETA, 1999).

A ingestão de fibra dietética em níveis moderados mostrou-se eficaz para a regulação dos níveis plasmáticos de glicose, colesterol e triglicerídios, assim como na prevenção de certas enfermidades degenerativas ou crônicas (câncer de cólon e reto, arteriosclerose, diabetes, etc.). Além disso, a fibra aumenta a saciedade e o volume fecal, servindo como meio de fermentação para a microflora bacteriana intestinal (LÓPEZ et al., 1997).

O National Cancer Institute recomenda ingestão diária de fibras de 25 a $35 \mathrm{~g}$ ou 10 a $13 \mathrm{~g} / 1000 \mathrm{Kcal}$. Também é aconselhável a proporção de 3:1 para ingestão de fibras insolúveis e solúveis (MAHAN e ESCOTTSTUMP, 1998).

Conforme SALMERON et al. (1997), o risco de desenvolver diabetes está ligado inversamente ao consumo de fibra de cereal e positivamente associado com a carga glicêmica. Afirmaram que os grãos deveriam ser consumidos pouco refinados para reduzir a incidência de diabetes.

Busca-se cada vez mais a inserção de cereais na alimentação mediante produtos versáteis, que possam ser preparados pelo consumidor. Neste sentido, vários alimentos ricos em fibras, proteínas, minerais e vitaminas vêm sendo elaborados em todo o mundo (TETTWEILER, 1991) como, por exemplo, biscoitos e pães enriquecidos (SILVA et al., 2001; PROTZEK; FREITAS; WASCZYNSKJ, 1998; DELAHAYE et al., 1994).

Os snacks são definidos como pequenas refeições, leves ou substanciais, podendo estar relacionados com os atributos "saudável" e/ou "diversão". Vários são os produtos classificados como snack, dentre os quais pode-se citar as minipizzas, biscoitos, pipocas e as barras de cereais (TETTWEILER, 1991). Segundo ESCOBAR et al. (1998), o consumo de alimentos snack apresenta crescimento constante.

O'NEILL et al. (2001) verificaram que barras de cereais administradas para pacientes hipercolesterolêmicos ajudam a reduzir os níveis do 
LDL-colesterol. Os principais aspectos considerados na elaboração desse produto incluem a escolha do cereal (aveia, trigo, arroz, cevada, milho), a seleção do carboidrato apropriado de forma a manter o equilíbrio entre o sabor e a vida de prateleira, o enriquecimento com vários nutrientes e sua estabilidade no processamento, o uso de fibra dietética e o papel de isoflavonas como ingrediente funcional (O'CARROL, 1999). Na seleção desses, os aspectos relevantes referem-se à percepção do consumidor quanto ao valor nutricional do produto. São preferidos os com baixo teor ou isentos de gordura, porém com alto aporte energético (ESCOBAR et al., 1998). Foi o que analisaram MITCHELL e BOUSTAIN (1990), em estudo piloto com 200 indivíduos, os quais classificaram as barras de cereais como produtos mais saudáveis do que os snacks tradicionais (doces, chocolates...). Por outro lado, BOWER e WHITTEN (2000) observaram que o atributo "saudável" não é tão importante. As características de textura, preço e aparência mostraram-se relevantes na aquisição desses produtos.

MITCHELL e BONSTAIN (1990) constataram que $62,5 \%$ dos consumidores de barras de cereais encontram-se na faixa entre $15 \mathrm{e}$ 24 anos.

O presente trabalho teve como objetivo elaborar barra de cereal caseira, como alternativa de baixo custo aos produtos comerciais.

\section{MATERIAL E MÉTODOS}

\subsection{MATERIAL}

Formulou-se receita básica de barra de cereal empregando biscoito de amido de milho (400 g), açúcar demerara (22 g), leite em pó desnatado (100 g), flocos de arroz (100 g), aveia em flocos (150 g), xarope de glicose de milho (624 g), uva passa (116 g) e damasco seco $(110 \mathrm{~g})$. Para estudo comparativo foram utilizadas barras de cereais comerciais de marcas brasileiras.

\subsection{FORMULAÇÃO}

Triturou-se o biscoito em triturador de alimentos até a obtenção de pó 
fino, ao qual foram incorporados os demais ingredientes secos. Após a mistura, adicionou-se uva passa inteira sem sementes e damasco seco, previamente, fracionado. Homogeneizou-se, novamente, a mistura para a inserção do xarope de glicose, o qual foi adicionado aos poucos até a obtenção de massa uniforme. Em seguida, distribuiu-se a massa em forma de aço inoxidável, previamente revestida com filme PVC. Realizou-se a prensagem com rolo de polietileno até espessura aproximada de $1 \mathrm{~cm}$. A massa permaneceu em repouso por cerca de $6 \mathrm{~h}$ para posterior desenformagem, corte e embalagem em laminado de alumínio (Figura 1).

\subsection{MÉTODOS}

\subsubsection{Análises físico-químicas}

Efetuaram-se as determinações (em duplicata) de umidade e substâncias voláteis a $105^{\circ} \mathrm{C}$, segundo a metodologia do Instituto Adolfo Lutz (1985), resíduo mineral fixo (cinzas) pelo método gravimétrico (930.22), proteínas pelo método Kjeldahl (991.20), extrato etéreo por extração em Soxhlet (963.15) e fibra alimentar total (985.29) pelo método enzimático gravimétrico, todos extraídos da AOAC (1998). Os carboidratos totais foram determinados por diferença entre 100 gramas da amostra e a soma total dos valores de proteínas, lipídios, resíduo mineral fixo e fibra alimentar (ASCAR, 1985). O valor calórico total foi calculado aplicando-se os valores de conversão para carboidratos (4), lipídios (9) e proteína (4).

\subsubsection{Análises Microbiológicas}

Foram realizadas determinações de Staphylococcus aureus, Salmonella sp., Coliformes a $45^{\circ} \mathrm{C}$ e Bacillus cereus conforme os métodos oficiais da AOAC (1998) números 2001.05, 967.25, 991.14 e 980.31, respectivamente.

\subsubsection{Análises Microscópicas}

Executou-se a pesquisa de sujidades, larvas, fragmentos de insetos e parasitas segundo a técnica 16.14.12/968.38b de BOESE e CICHOWICZ (1995), extraída da AOAC. 
FIGURA 1 - FLUXOGRAMA DE ELABORAÇÃO DA BARRA DE CEREAL

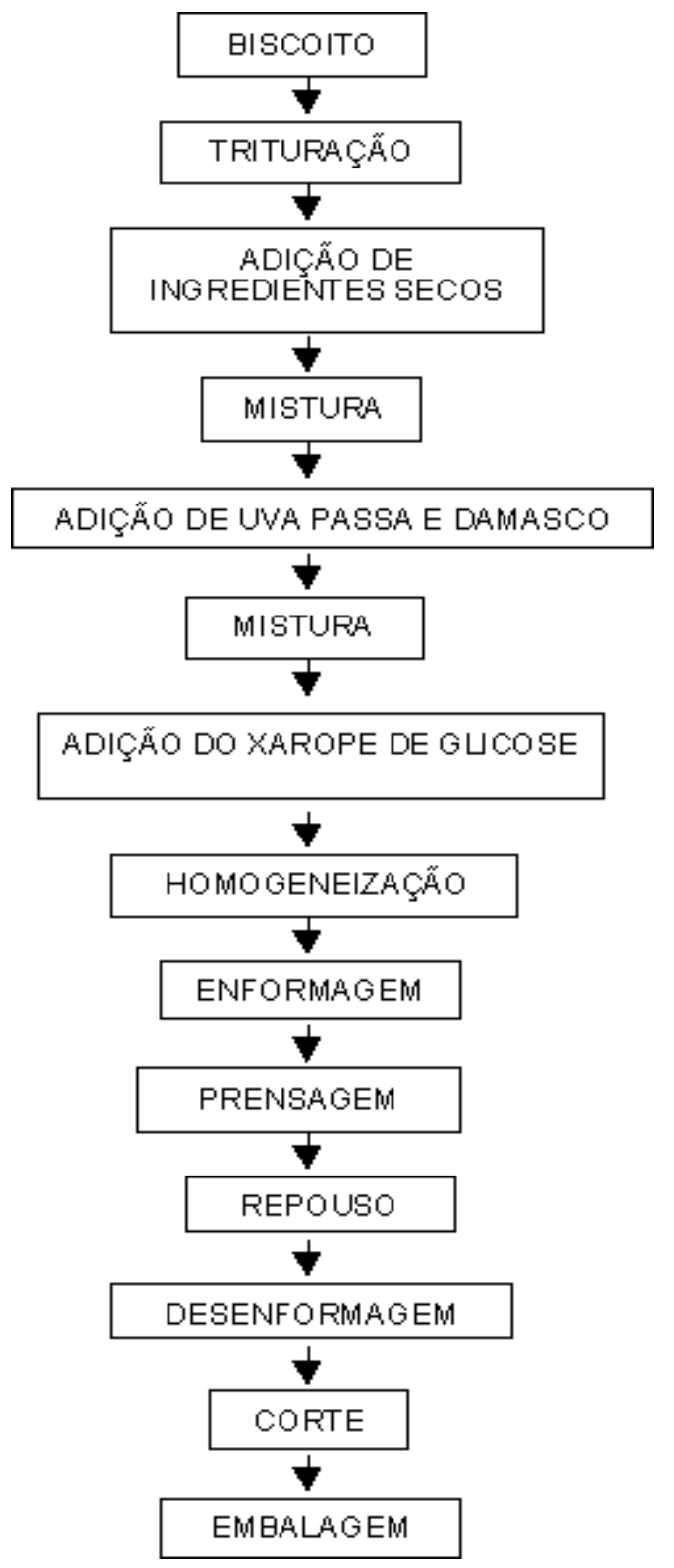




\subsubsection{Análise Sensorial}

A análise sensorial foi realizada com a barra de cereal formulada (G1) e duas outras barras de marcas diferentes, obtidas no comércio de Recife (G2 e G3), apresentando características similares entre si. Foram selecionados 11 painelistas treinados, os quais definiram os termos descritivos relacionados ao produto que serviram de base para a elaboração de glossário (Figura 2).

\section{FIGURA 2 - GLOSSÁRIO DOS TERMOS UTILIZADOS NA ANÁLISE SENSORIAL DA BARRA DE CEREAL *}

\begin{tabular}{|c|c|}
\hline ATRIBUTO & DESCRI` O GERAL \\
\hline AparCficia Geral & $\begin{array}{l}\text { Avalia a global das caracter sticas visuais, incluindo defeitos de superf cie e } \\
\text { de fundo, brilho e cor. }\end{array}$ \\
\hline Cor & $\begin{array}{l}\text { Sensa o produzida pela estimula a o da retina pelos raios luminosos de } \\
\text { comprimento de onda vari/tteis enquadrados na faixa do espectro vis vel. }\end{array}$ \\
\hline Brilho & Aspecto de superf cie reluzente. \\
\hline Uniformidade & $\begin{array}{l}\begin{array}{l}\text { Caracter stica referente } \\
\text { deformidades na superf cie. }\end{array} \\
\text { compacta } \stackrel{a}{\circ} \text { o do produto, ou ausOfficia de }\end{array}$ \\
\hline Firmeza & $\begin{array}{l}\text { Propriedade de textura em rela }{ }^{a} 0 \text { for a necess AEia para comprimir e cortar a } \\
\text { amostra com faca. }\end{array}$ \\
\hline ResistCficia ao corte & $\begin{array}{l}\text { For a necessffia para cortar o produto que varia de baixa, mødia e alta } \\
\text { resistCficia ao corte. }\end{array}$ \\
\hline Adesividade & $\begin{array}{l}\text { Propriedade de textura em rela }{ }^{a} 0 \text { for a necess fसila para remover o produto } \\
\text { que adere ao palato e/ou aos dentes. }\end{array}$ \\
\hline Coesividade & $\begin{array}{l}\text { Propriedade de textura percebida na cavidade oral em rela }{ }^{a} 0 \text { ao ponto limite } \\
\text { em que o material pode ser deformado antes de se romper. }\end{array}$ \\
\hline Croc ncia & $\begin{array}{l}\text { Caracter stica de textura associada ao fato de algum ingrediente fraturar-se em } \\
\text { peda os e estalar ao serem mastigados. }\end{array}$ \\
\hline Mastigabilidade & $\begin{array}{l}\text { Propriedade de textura percebida pelo contato do alimento com os dentes e } \\
\text { palato. }\end{array}$ \\
\hline Odor de caramelo & $\begin{array}{l}\text { Sensa o olfativa sentida pela transforma }{ }^{a} \text { o do a car em caramelo } n^{a} 0- \\
\text { queimado. }\end{array}$ \\
\hline Odor adocicado & Sensa $\stackrel{a}{0}$ olfativa percebida por subst ncias que conferem o odor doce. \\
\hline Odor de frutas & 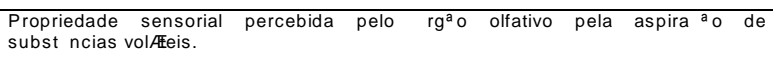 \\
\hline Do ura & $\begin{array}{l}\text { Propriedade sensorial de subst ncias puras ou misturas que produzem o sabor } \\
\text { doce. }\end{array}$ \\
\hline Acidez & $\begin{array}{l}\text { Propriedade sensorial de subst ncias puras ou misturas que produzem o sabor } \\
\text { Ateido. }\end{array}$ \\
\hline Sabor de mel & Refere-se ao odor e sabor de mel. \\
\hline Agridoce & Atributo de odor e sabor obtido pela combina ${ }^{a}$ o do sabor Aeido e doce. \\
\hline Salgado & $\begin{array}{l}\text { Propriedade sensorial de subst ncias puras ou misturas que produzem o sabor } \\
\text { salgado. }\end{array}$ \\
\hline Qualidade global & $\begin{array}{l}\text { Soma de todos os fatores de qualidade que contribu ram para a determina o } \\
\text { do grau de aceita } 0 \text { do produto. }\end{array}$ \\
\hline
\end{tabular}

*Adaptado de MORI, YOTSUYANAGI e FERREIRA (1998). 
Foram oferecidas aos provadores as três barras envoltas em papel alumínio e etiquetadas com códigos aleatórios. Para padronização das respostas utilizou-se o glossário dos termos. Cada painelista, individualmente, realizou a análise descritiva quantitativa (QDA) dos produtos, utilizando escalas não-estruturadas $\mathrm{com} 10 \mathrm{~cm}$ de longitude para cada atributo listado (Figura 3) de acordo com ANZALDÚAMORALES (1994). Os valores de cada atributo foram obtidos pela medida da distância da extremidade esquerda da escala (ponto zero) até a marca vertical assinadada pelo painelista. As notas (variando de zero a dez) foram transformadas em escalas decimais na construção dos gráficos de perfil para melhor visualização dos resultados.

\subsubsection{Análise Estatística}

Aos resultados das análises aplicaram-se os testes estatísticos de Análise de Variância (ANOVA) e de Tukey, admitindo-se níveis de significância de 0,05 e 0,01 (STATSOFT, 2000).

\section{RESULTADOS E DISCUSSÃO}

\subsection{COMPOSIÇÃO FÍSICO-QUÍMICA}

Os resultados da composição centesimal da barra de cereal elaborada estão ilustrados na Tabela 1.

\section{TABELA 1 - COMPOSIÇÃO CENTESIMAL DA BARRA DE CEREAL CASEIRA}

\begin{tabular}{|c|c|}
\hline AnAfises & Barra de cereal composi $\stackrel{a}{0} / 100 \mathrm{~g}$ \\
\hline Calorias (Kcal) & 354,6 \\
\hline Umidade $(g)$ & 7,63 \\
\hline Cinzas $(g)$ & 1,13 \\
\hline Carboidrato $(\mathrm{g})$ & 80,85 \\
\hline Lip dios $(g)$ & 0,68 \\
\hline Prote nas (g) & 6,27 \\
\hline Fibras $(g)$ & 3,44 \\
\hline
\end{tabular}


FIGURA 3 - MODELO DE QUESTIONÁRIO UTILIZADO NA ANÁLISE SENSORIAL DESCRITIVA DA BARRA DE CEREAL

Nome:

Data:

Instru । es: Marque com um tra o vertical nas escalas abaixo a posi ̊ㅡ o que identifique melhor a intensidade da caracter stica avaliada.

AparCria

AparCøecia

geral

Muito ruim $\quad$ Excelente

Cor

Marrom claro Marrom escuro

Brilho

Uniformidade

Fraco

Textura ( $\mathrm{n}^{\mathrm{a}} \mathrm{o}$ oral)

Firmeza

Resistạcia

ao corte

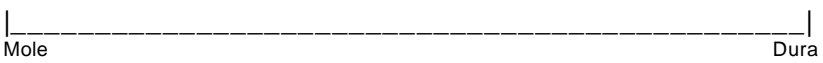

I.

Baixa Alta

Textura (oral)

Adesividade

Coesividade

Croc ncia

Mastigabilidade

Odor

Caramelo

Adocicado

Frutas

Fraca

Fraca 20

Pouca _____________ Muita

Pouca

Sabor

Doce

cido

Mel

Agridoce

Salgado

Qualidade

Global

Fraco

Fraco


A barra de cereal apresentou baixos níveis de gordura $(0,68 \%)$ e elevado teor de carboidratos $(80,85 \%)$, sendo esse o maior contribuinte calórico do produto.

O valor encontrado para fibras $(3,44 \mathrm{~g} / 100 \mathrm{~g})$ permite classificar a barra de cereal caseira como produto com teores moderados de fibra, conforme MATTOS e MARTINS (2000), por enquadrar-se na faixa entre 2,4 e $4,4 \mathrm{~g} / 100 \mathrm{~g}$ de fibras.

A comparação da composição centesimal da barra de cereal formulada (G1) com a das industrializadas (G2 e G3) consta da Tabela 2.

\section{TABELA 2- COMPOSIÇÃO CENTESIMAL DAS BARRAS FORMULADA (G1) E COMERCIAIS (G2 E G3)}

\begin{tabular}{l|c|c|c}
\hline \multicolumn{1}{c|}{ Composi a o p/25 g } & G1 & G2 $^{*}$ & G3 $^{*}$ \\
\hline Calorias (Kcal) & 88,65 & 90,00 & 110,00 \\
Carboidratos (g) & 20,21 & 19,00 & 17,00 \\
Lip dios (g) & 0,17 & 1,00 & 4,00 \\
Prote nas (g) & 1,57 & 1,00 & 1,00 \\
Fibras (g) & 0,86 & 1,00 & 1,00 \\
\hline
\end{tabular}

* Composição extraída dos rótulos.

A comparação por porção do produto $(25 \mathrm{~g})$ mostra que a barra formulada apresentou valores bem próximos aos das industrializadas no que se refere ao aporte calórico, carboidratos e proteínas (pouco maior na barra G1). Entretanto, revelou teores de lipídios (de 83,0\% a $95,7 \%$ ) mais baixos que os das barras comerciais.

O teor de fibras mostrou-se $14 \%$ menor na barra G1, sendo sugerida a substituição do biscoito pela versão integral e a inserção de cereais integrais na formulação para incrementar o aporte de fibras.

\subsection{ANÁLISE MICROBIOLÓGICA}

Não foi identificada a presença de Staphylococcus aureus, Salmonella sp., Coliformes a $45^{\circ} \mathrm{C}$ e Bacillus cereus no produto (Tabela 3 ), que 
mostrou-se de acordo com a Resolução n.12 do Ministério da Saúde (BRASIL, 2001).

\section{TABELA 3 - RESULTADOS DO ENSAIO MICROBIOLÓGICO}

\begin{tabular}{l|c}
\hline Ensaios & Resultados \\
\hline Salmonella em $25 \mathrm{~g}$ & AusC̄́cia \\
Coliformes a 45 "C (UFC/g) & $<10$ \\
Staphilococcus aureus (UFC/g) & $<10$ \\
Bacillus cereus (UFC/g) & $<10$ \\
\hline
\end{tabular}

\subsection{ANÁLISE MICROSCÓPICA}

Os ingredientes utilizados na formulação da barra de cereal atenderam às exigências da Resolução 12/78, da CNNPA/MS (BRASIL, 1978), quanto aos ensaios microscópicos não sendo identificados elementos estranhos no produto (sujidades, fragmentos de insetos, larvas e parasitos).

\subsection{ANÁLISE SENSORIAL}

Os resultados médios obtidos para cada característica sensorial das barras G1, G2 e G3 estão apresentados na Tabela 4 e na Figura 4.

Em termos de aparência, a cor e o brilho da barra formulada (G1) mostraram-se estatisticamente diferentes $(p<0,05$ e $p<0,01$, respectivamente) em relação à barra G3. Tal fato ocorreu, provavelmente, devido à utilização de ingredientes de coloração escura (como o açúcar demerara) e à característica brilhante do xarope de glicose de milho.

A barra formulada (G1) apresentou-se mais firme que a barra G3 $(p<0,01)$ e maior resistência ao corte que ambas as barras comerciais $(p<0,05)$. O xarope de glicose utilizado para formação de liga adquire consistência de massa compacta, promovida pela aderência entre o 
biscoito em pó e o xarope, apresentando maior resistência à deformação.

\section{TABELA 4 - VALORES MÉDIOS DOS ATRIBUTOS SENSORIAIS DAS BARRAS FORMULADA (G1) E COMERCIAIS (G2 E G3)}

\begin{tabular}{|c|c|c|c|}
\hline Atributos & G1 & G 2 & G 3 \\
\hline AparCEcia & & & \\
\hline aparCfrcia geral & $5,40-1,70^{a}$ & $6,57-2,65^{\mathrm{a}}$ & $4,19-2,29^{a}$ \\
\hline cor & $3,39-2,64^{a}$ & $2,05-2,21^{a b}$ & $0,87-1,45^{b}$ \\
\hline brilho & $4,50-2,20^{a}$ & $3,90-2,35^{a}$ & $1,07-1,34^{b}$ \\
\hline $\begin{array}{l}\text { uniformidade } \\
\text { Textura } n^{2} \text { o oral }\end{array}$ & $6,20-2,26^{a}$ & $5,05-2,23^{a}$ & $6,30-2,81^{a}$ \\
\hline firmeza & $3,04-2,06^{a}$ & $5,16-2,15^{\mathrm{ab}}$ & $\begin{array}{l}5,97-2,14^{b} \\
2,52-232^{b}\end{array}$ \\
\hline Textura oral & $7,00-2,00$ & $2,00-2,17$ & \\
\hline adesividade & $3,65-2,10^{a}$ & $2,85-2,84^{a}$ & $2,25-2,55^{a}$ \\
\hline coesividade & $4,06-2,17^{a}$ & $4,98-3,23^{a}$ & $3,32-2,70^{a}$ \\
\hline croc ncia & $4,45-1,26^{a}$ & $4,83-2,77^{a}$ & $4,14-2,46^{a}$ \\
\hline $\begin{array}{l}\text { mastigabilidade } \\
\text { Odor }\end{array}$ & $4,77-2,23^{a}$ & $5,89-2,66^{a}$ & $5,05-2,27^{a}$ \\
\hline caramelo & $3,45-3,14^{a}$ & $1,66-2,56^{a}$ & $2,56-2,68^{a}$ \\
\hline adocicado & $6,30-1,94^{a}$ & $3,41-2,09^{b}$ & $5,35-2,48^{a b}$ \\
\hline $\begin{array}{l}\text { frutas } \\
\text { Sabor }\end{array}$ & $3,60-1,79^{a}$ & $5,29-3,17^{\mathrm{a}}$ & $6,02-3,00^{a}$ \\
\hline doce & $6,57-1,80^{a}$ & $4,29-2,79^{b}$ & $6,30-1,87^{\mathrm{c}}$ \\
\hline FEcido & $1,97-2,03^{a}$ & $1,30-2,00^{a}$ & $0,49-0,45^{a}$ \\
\hline mel & $4,44-2,75^{a}$ & $1,43-1,46^{b}$ & $2,15-2,26^{a b}$ \\
\hline agridoce & $1,02-1,60^{a}$ & $1,40-1,72^{a}$ & $0,84-1,29^{a}$ \\
\hline salgado & $0,75-1,44^{a}$ & $1,05-1,99^{a}$ & $0,39-0,42^{a}$ \\
\hline Qualidade Global & $6,88-1,67$ & $6,12-2,54^{a}$ & $6,45-1,26^{a}$ \\
\hline
\end{tabular}

Letras iguais na mesma linha indicam que não houve diferença significativa no Teste de Turkey ao nível de 5\% de significância.

A avaliação sensorial do atributo textura oral não evidenciou diferença estatística significante entre as três barras. Sendo a textura um dos fatores levados em consideração na aquisição de barras de cereal (BOWER e WHITTEN, 2000), a formulação caseira pode alcançar a aceitação do consumidor.

$\mathrm{O}$ atributo odor adocicado mostrou-se bem acentuado na barra $\mathrm{G} 1$ (diferença significativa $p<0,05)$, causado pela utilização de dois tipos de carboidratos simples (sacarose e glicose).

O sabor doce foi o único aspecto diferente entre as três barras $(p<0,05)$, 
sendo mais acentuado na barra G1. Já o sabor de mel diferiu entre as barras G1 e G2. Tais dados sugerem redução da quantidade de açúcar na formulação, especialmente de sacarose que apresenta doçura relativa maior que a glicose.

\section{FIGURA 4 - PERFIS DA BARRA FORMULADA (G1) E COMERCIAIS (G2 E G3)}

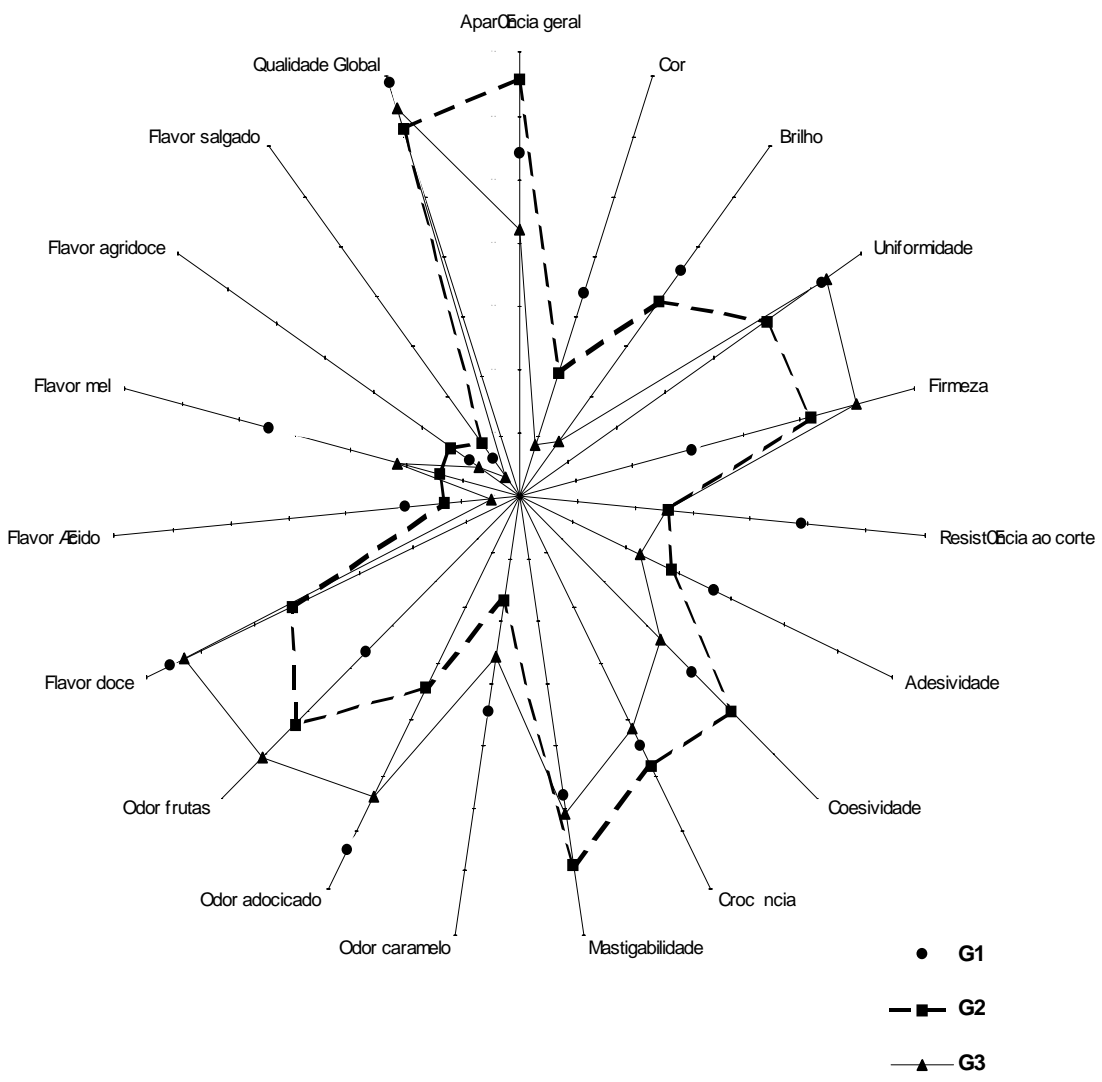

Não foi constatada diferença significativa entre as barras quanto à qualidade global. Nesse atributo, a barra G1 obteve nota superior às das barras G2 e G3 (Figura 4). 


\section{CONCLUSÃO}

Os resultados obtidos evidenciaram a viabilidade de se obter barra de cereal mediante formulaçao simples como alternativa aos produtos comerciais. A barra de cereal formulada apresentou bom aporte calórico e de fibras, assim como baixo teor em gorduras e aceitação global superior à das bananas comerciais. Concluiu-se que o produto atende às especificações sanitárias, nutricionais e sensoriais.

\section{Abstract}

\section{ELABORATION AND GLOBAL EVALUATION OF A HOME-MADE CEREAL $B A R$}

A basic recipe of cereal bar was formulated, by employing corn starch biscuit, demerara sugar, skim powder milk, rice flakes, oat flakes, corn glucose syrup, raisin and dried apricot, as alternative to the bars available in the market. To evaluate the centesimal composition and the acceptance of this home-made product, two commercial bars were utilized as reference parameter. The product was submitted to carbohydrate, lipids, proteins and fiber determinations and to sensory analysis. The obtained results demonstrated that the formulated bar showed very near values to those found in industrialized bars as it concerns the presence of calories, carbohydrates and proteins. However, lipid contents were $83 \%$ to $95.7 \%$ lower than the commercial bars. Fiber content was 14\% lower in the home-made bar, suggesting that the substitution of the biscuit by the whole version and the insertion of whole cereals in the formulation to increment the fiber content. The formulated bar obtained global acceptance superior to the reference bars, representing an option to fiber supplementation in the diet. It was concluded that the product assists the sanitary, nutritional and sensory specifications.

KEY-WORDS: CEREAL BAR; DIETARY FIBER; SENSORY ANALYSIS.

\section{REFERÊNCIAS}

1 ANZALDÚA-MORALES, A. La evaluación sensorial de los alimentos en la teoría y la práctica. Zaragoza: Acribia, 1994. 198 p.

2 AOAC. Association of Official Analytical Chemists. Official method of analysis of AOAC international. $16^{\text {th }}$ ed. Arlington, 1998. v.1.

3 ASCAR, J.M. Aspectos bromatológicos e legais. São Leopoldo, Rio Grande do Sul: Usininos, 1985. 90 p.

4 BOESE, J.; CICHOWICZ, S. M. Extraneous materials -isolation. In: AOAC. Official methods of analysis of Association of Official Analytical Chemists International. $17^{\text {th }}$ ed. Arlington, 1995. v. 1, Ch.16, p.42-45. 
5 BOWER, I. A.; WHITTEN, R. Sensory characteristics and consumer liking for cereal bar snack foods. Journal of Sensory Studies, v. 15, n. 3, p. 327-345, 2000.

6 BRASIL. Ministério da Saúde. Secretaria de Vigilância Sanitária. Resolução CNNPA n. 12 de 24 de julho de 1978. Normas Técnicas e Especiais para alimentos e bebidas. Disponível em: <http://www.anvisa.gov.br/legisl/resol/ 12_78_cereais.htm>. Acesso em: 20/02/2003.

7 BRASIL. Ministério da Saúde. Secretaria de Vigilância Sanitária. Resolução RDC n.12 de 2 de janeiro de 2001. Regulamento Técnico sobre os Padrões microbiológicos para alimentos. Disponível em: <http://www.anvisa. gov.br/legisl/ resol/12_01rdc.htm>. Acesso em: 10/02/2003.

8 DELAHAYE, E.P.; CEDRES, M.; ALVARADO, A.; CIOCCIA, A. Substitución del afrecho de trigo por harina de almendra desgrasada de palma aceitera rica fuente de fibra dietética en la elaboración de galletas y panes. Archivos Latinoamericanos de Nutrición, v.44, n.2, p.122-128, 1994.

9 DIETZ, W. H. Health consequences of obesity in youth: childhood predictors of adult disease. Pediatrics, v. 101, p. 518-528, 1998.

10 ESCOBAR, A.B.; ESTÉVEZ, A.M.A.; TEPPER, A.L.; AGUAYO, M.R. Características nutricionales de barras de cereals y maní. Archivos Latinoamericanos de Nutrición, v. 48, n. 2, p.156-159, 1998.

11 GUIMARÃES, E.V.; GOULART, E.M.A.; PENNA, F.J. Dietary fiber intake, stool frequency and colonic transit time in chronic functional constipation in children. Brazilian Journal of Medical and Biological Research, v.34, p. 1147-1153, 2001.

12 GUTKOSKI, L. C.; TROMBETTA, C. Avaliação dos teores de fibra alimentar e de beta-glicanas em cultivares de aveia (Avena sativa L). Ciência e Tecnologia de Alimentos, v. 19, n. 3, p. 387-390, 1999.

13 INSTITUTO ADOLPHO LUTZ. Normas analíticas do Instituto Adolfo Lutz: métodos químicos e físicos de análises de alimentos. 3.ed. São Paulo: Guanabara Dois, 1985. v. 1.

14 HILL, J. O.; TRWBRIDGE, F. L. Childhood obesity: future directions and research priorities. Pediatrics, v.101, n. 3, p.570-574, 1998.

15 LÓPEZ, G.; ROS, G.; RINCÓN, F.; PERIAGO, M.J.; MARTÍNEZ, C.; ORTUÑO, J. Propiedades funcionales de la fibra dietética. Mecanismos de acción en el tracto gastrointestinal. Archivos Latinoamericanos de Nutricion, v.47, n.3, p.203207, 1997.

16 MAHAN, L.K.; ESCOTT-STUMP, S. Krause: alimentos, nutrição e dietoterapia. 9.ed. São Paulo: Roca, 1998. p. 43.

17 MATTOS, L. L.; MARTINS, I. S. Consumo de fibras alimentares em população adulta. Revista de Saúde Pública, v. 34, n. 1, p. 50-55, 2000. 
18 MITCHELL, V. W; BOUSTAIN, P. Cereal bars: a perceptual, chemical and sensory analysis. British Food Journal, v. 92, n. 5, p.17-22, 1990.

19 MORI, E.E.M.; YOTSUYANAGI, K.; FERREIRA, V.L. Análise sensorial de goiabadas de marcas comerciais. Ciência e Tecnologia de Alimentos, Campinas, v.18, n.1, p. 105-110, jan./abr. 1998.

20 O'CARROL, P. Boosting cereal bars. World of Ingredients, p.36-38, Mar./Apr., 1999.

21 O'NEILL, F.H.; MANDENO, R.; THOMPSON, G.R.; SEED, M. Enhancement of cholesterol-lowering effect of atorvastatin by stanol ester cereal bars. Atherosclerosis Supplements, v.2, n.1, p. 110, May 2001.

22 PENTEADO, R. L. B. Fibras vegetais na alimentação humana. Boletim SBCTA, Campinas, v.15, n.3, p. 274-302, 1981.

23 PROTZEK, E.C.; FREITAS, R.J.S.; WASCZYNSKJ, N. Aproveitamento do bagaço de maçã na elaboração de biscoitos ricos em fibra alimentar. Boletim do CEPPA, Curitiba, v.16, n.2, p.263-275, jul./dez. 1998.

24 SALMERON, J. et al. A high-fibre diet may reduce the risk of diabetes. Journal American Medical Association, v.277, p. 472, 1997.

25 SILVA, M.R.; SILVA, M.S.; MARTINS, K.A.; BORGES, S. Utilização tecnológica dos frutos de jatobá-do-cerrado e de jatobá-da-mata na elaboração de biscoitos fontes de fibra alimentar e isentos de açúcares. Ciênc. Tecnol. Aliment., Campinas, v.21, n.2, p.176-182, maio-ago. 2001.

26 STATSOFT. Statistica for windows [computer program manual]. Tulsa, OK, 2000.

27 TETTWEILER, P. Snack foods worldwide. Food Technology, v.45, p.58-62, 1991.

28 VIEIRA, V. C. R. et al. Hábitos alimentares e consumo de lanches. Nutrição em Pauta, São Paulo, n. 46, p.14-20, jan/fev. 2001.

29 VÍTOLO, M.R.; AGUIRRE, A.N.C.; NETO, U.F.; MORAIS, M.B. Estimativa do consumo de fibra alimentar por crianças de acordo com diferentes tabelas de composição de alimentos. Archivos Latinoamericanos de Nutrición, v.48, n.2, p.141-145, 1998. 